\title{
Four new species of Neotropical spittlebugs (Hemiptera, Cercopidae, Tomaspidinae)
}

\author{
Danice H. Costes ${ }^{1} \&$ Michael D. Webb ${ }^{2}$
}

'Formerly, University of Raleigh, North Carolina, USA. E-mail: dcostes@troyst.edu

${ }^{2}$ The Natural History Museum. Cromwell Road, London SW7 5BD, UK. E-mail: mew@nhm.ac.uk

\begin{abstract}
Resumo. Quatro espécies novas de cigarrinhas neotropicais (Hemiptera, Cercopidae, Tomaspidinae). As seguintes espécies novas de Cercopidae da América do Sul são descritas: Ischnorhina quadrimelasma sp. nov. (Bolívia), Laccogrypota quadrilineata sp. nov. (Bolívia), (Neolaccogrypota youngi sp. nov. (Peru) e Neosphenorhina schombergi sp. nov. (Brasil).

Palavras-Chave. Cercopidae; Hemiptera; Neotropical; novas espécies.

Abstract. The following new species of South American Cercopidae, are described: Ischnorhina quadrimelasma sp. nov. (Bolivia), Laccogrypota quadrilineata sp. nov. (Bolivia), (Neolaccogrypota youngi sp. nov. (Peru), and Neosphenorhina schombergi sp. nov. (Brazil).
\end{abstract}

Keywords. Cercopidae; Hemiptera; Neotropical; new species.

The Cercopoidea (froghoppers) form the largest group of sap-sucking insects. Over four hundred species of the largest family (Cercopidae) are present in South America, of which some are important pests of pasture grasses and sugar cane. In the present paper four new species are described from this region. These species were originally treated as manuscript names by the senior author (COSTES 1971). Due to poor early descriptions, lack of adequate keys and details of the male genitalia, identification to genus and species is often difficult without access to a reference collection. Confirmation that the species described herein are new was made possible by a comparison with nearly all New World cercopid species, as part of a review of the group in progress (CARVALHO \& WeBB, in prep.). The placement to genus has been made by comparison with similar described species present in The Natural History Museum, London.

Abbreviations. AMNH: American Museum of Natural History, New York, USA; BMNH: The Natural History Museum, London, UK; NCSU: North Carolina State University, Raleigh, NC, USA; USNM: National Museum of Natural History, Washington, DC, USA.

\section{Ischnorhina quadrimelasma sp. nov.}

(Figs. 1, 5-7)

Length: male (x1), $17.6 \mathrm{~mm}$.

Head shiny red; rostrum dark brown. Thorax reddish-black; pronotum shiny red. Fore wings (Fig. 1) red with a small dark brown spot on basal third of corium and a larger brown mark apically. Abdomen black. Parameres (Fig. 7) with apical process relatively narrow. Aedeagus (Figs. 5-6) elongate with a very short acute subapical process on each side and a flange-like process on each side situated at c. 0.36 length.
Holotype male. BOLIVIA: Cristal Mayu, 5.XII.1949, L.E. Peña (NCSU, on indefinite loan to USNM).

Remarks. This species can be distinguished by its dark brown fore wing markings and narrow aedeagal shaft.

\section{Laccogrypota quadrilineata sp. nov.}

(Figs. 2, 8-10)

Length: male (x1), $14.9 \mathrm{~mm}$.

Head and thorax reddish, shiny on pronotum; rostrum blackish; forewings (Fig. 2) red with two longitudinal metallic dark brown lines, one rimming costal margin, the other a wider band covering most of clavus and posterior portion of corium. Anterior and middle legs with coxa reddish-black, trochanter, femur, tibia and tarsus dark brown; hind legs with coxa and trochanter reddish-brown, femur light brown, tibia and tarsus dark brown. Abdomen black. Aedeagus (Figs. 8-9) with apical half strongly expanded in lateral aspect and densely spinulate; with a very small subapical acute processes on each side.

Holotype male. BOLIVIA: Cristal Mayu, 9.XII.1949, L. E. Peña (NCSU, on indefinite loan to USNM). Paratypes: 2 male, same data as holotype except 15.VIII.1949 and 7.VIII.1949; 1 male, no data (NCSU and $\mathrm{BMNH}$ )

Remarks. The species is similar to L. valida (Distant) but differs in having the dark brown bands of the fore wings not extended around the apex and the aedeagus narrower apically in lateral view.

Neolaccogrypota youngi sp. nov. (Figs. 4, 11-13)

Length: male (x1), $13.8 \mathrm{~mm}$. 

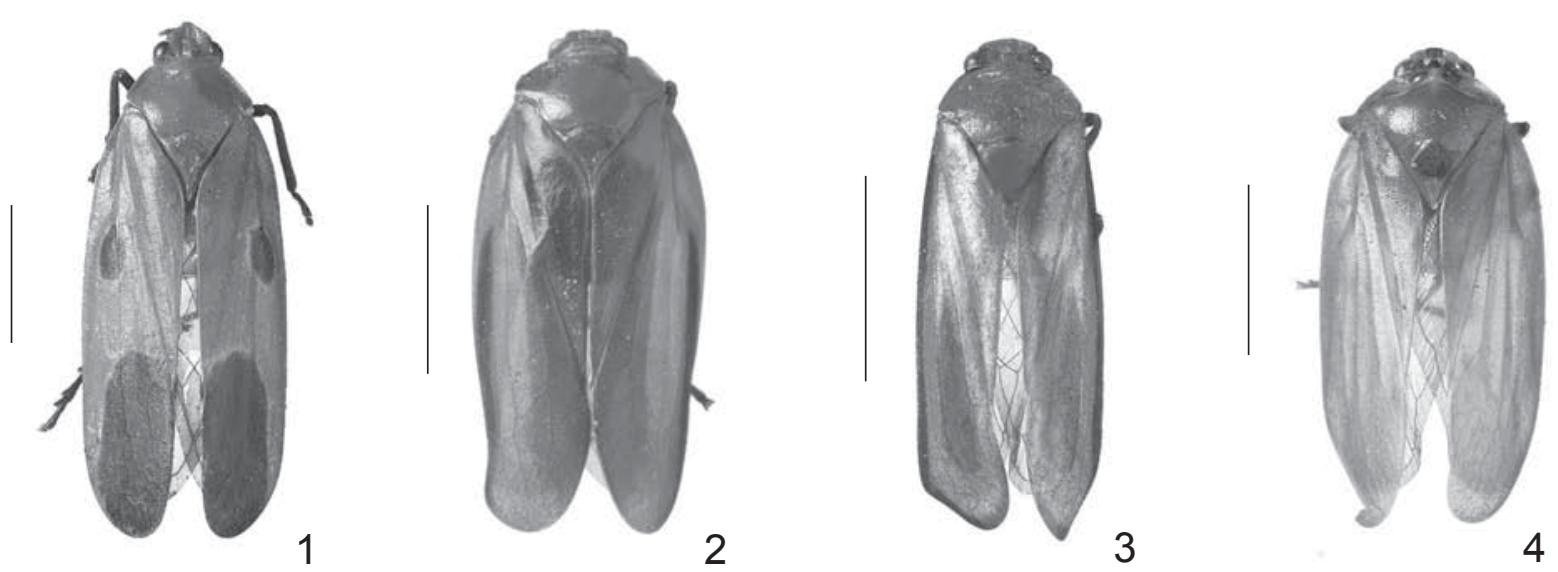

Figs. 1-4. Dorsal habitus (holotypes, pins digitally removed, scale line $=5 \mathrm{~mm}$ ). 1, Ischnorhina quadrimelasma; 2, Laccogrypota quadrilineata; 3, Neosphenorhina schombergi; 4, Neolaccogrypota youngi.
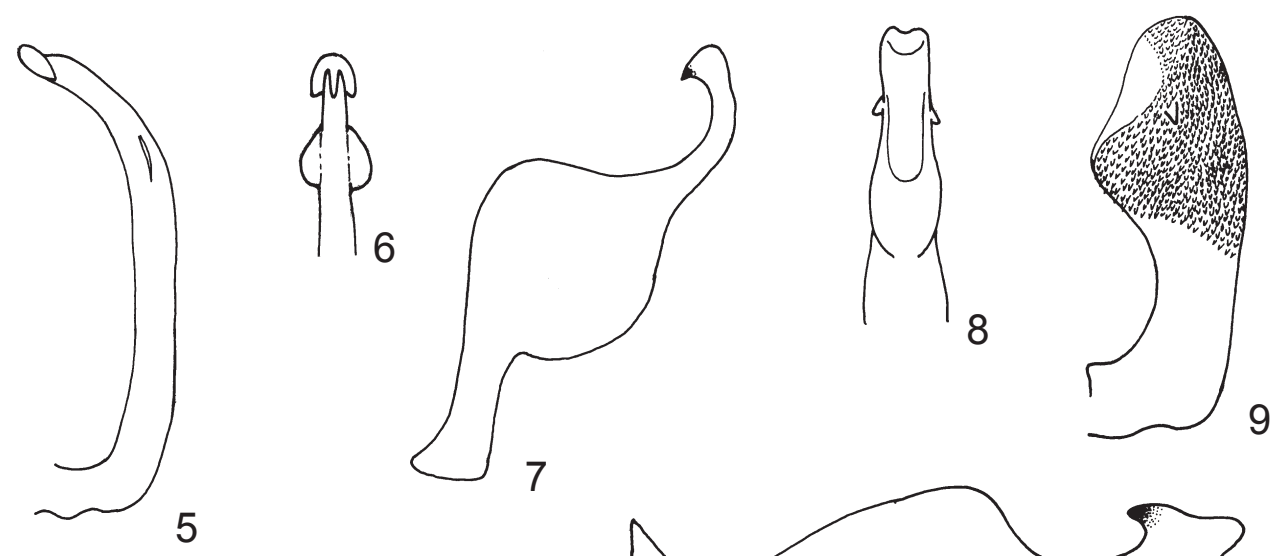

5
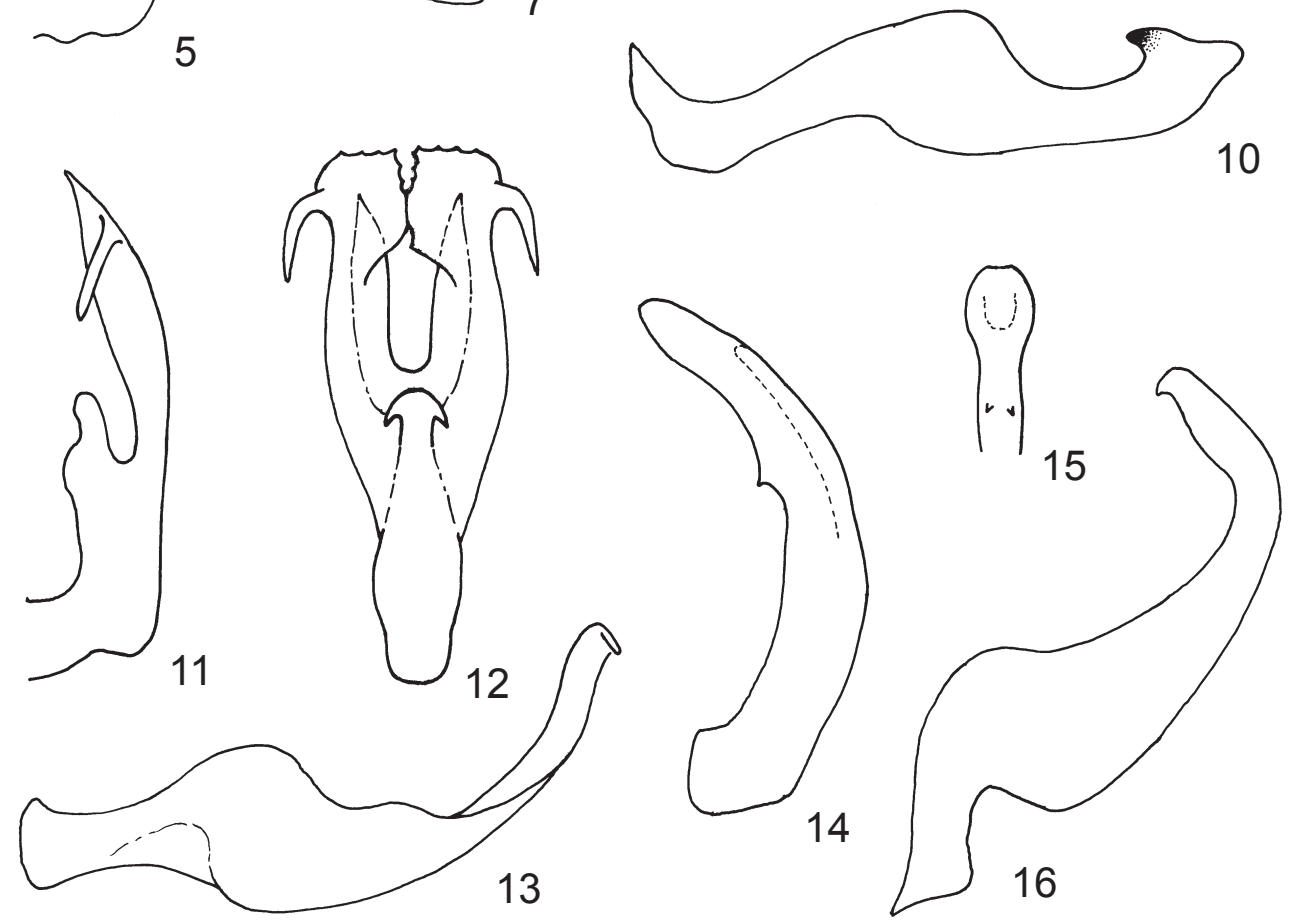

Figs. 5-16. Male genitalia (holotypes). 5-7, Ischnorhina quadrimelasma, 5, 6, aedeagus (left lateral and apex ventral view, respectively), 7, left style (lateral view); 8-10, Laccogrypota quadrilineata, 8, 9, aedeagus (left lateral and dorsal view, respectively), 10, left paramere (lateral view); 11-13, Neolaccogrypota youngi, 11, 12, aedeagus (lateral and dorsal view, respectively), 13, left style (lateral view); 14-16, Neosphenorhina schombergi, 14, 15, aedeagus (left lateral and apex dorsal view, respectively), 16, left style (lateral view). 
Head with clypeus stramineous, anteromedian portion of clypeus black; frons dark brown; vertex black; antennal ledge orangish; rostrum with second segment reddish, third segment dark brown. Thorax stramineous ventrally; pronotum with proximal 0.25 orangish with two brown spots against head near median carina, remainder of pronotum brown; fore wings (Fig. 4) hyaline light brown with costal margin rimmed in dull red. Legs reddish with apex of fore and mid femur and apex of tibia black; tarsus yellowish and brown. Aedeagus (Figs. 1112) with apex membranous and margins notched, very broad apically in dorso-ventral view; subapical processes moderately long.

Holotype male. PERU: Santa Isabel, Dept. Cusco, 11.XI.1951, F. L. Woytkowski (NCSU, on indefinite loan to USNM).

Remarks. This species is similar to $N$. nigricans Lallemand in the male genitalia but differs in its smaller size, paler colour and broader aedeagus in dorso-ventral view. Jr.

This species is named in honor of Dr. David Allan Young

\section{Neosphenorhina schombergi sp. nov.}

(Figs. 3, 14-16)

Length: male (x1), 12.0; female (x1), $12.8 \mathrm{~mm}$.

Male. Head red, distal tip of anteclypeus, dorsal margin of eyes socket, antennae, rostrum, dark brown; thorax red except the sternum which is reddish-black; pronotum sanguineous; fore wings (Fig. 3) reddish-hyaline with costal margin including apex rimmed with dark brown, a small area at base of clavus and corium clear and medial area of wing with a longitudinal smoky-black band. Fore coxa reddish-black, fore trochanter, mid coxa and mid trochanter black, fore and mid femur red with distal part black; hind legs with coxa and trochanter red, femur reddish-black; tibia and tarsi black. Parameres (Fig. 16) with apical process very long and narrow, upturned. Aedeagus in lateral view (Fig. 14) evenly curved and tapered from base to apex; apex of shaft, in dorso-ventral view (Fig. 15), slightly expanded; a very short acute processes on each side of dorsal surface, slightly distad of midlength.

Female. Colour as in male but with head and thorax stramineous; antennae black except basal portion of first segment which is reddish; rostrum with second segment yellowish-brown, third segment dark brown. Fore legs with coxa stramineous, trochanter yellowish-brown, femur yellowish, black distally; middle and posterior legs with coxa, trochanter, and most of femur stramineous.

Holotype male. BRAZIL: Corupá (Hansa Humboldt), Santa Catarina, XI.1930, A. Maller (AMNH). Paratype: female, BRAZIL: Campo Bello, XI.1932 (AMNH).

Remarks. Externally this species is similar to N. festa (Germar) but differs in having the costal brown band marginal rather than sub-marginal and in the male genitalia by the more ventral aedeagal processes and the style apical process more elongate.

This species is named in honor of Mr. Orville Schomberg, a friend and entomologist, who inspired the senior author.

Acknowledgements. The authors wish to thank Robert L. Blinn (NCSU) for the loan of material under his care and Lew Deitz (NCSU) for his help during the course of the work.

\section{REFERENCE}

Costes, D. H. 1971. Comparative morphological study of four tribes of the Cercopinae (Homoptera: Cercopidae). Thesis for Doctor of Philosophy. Department of Entomology, University of Raleigh, USA, $120 \mathrm{p}$. 